\title{
Use of del Nido cardioplegia in adult cardiac surgery
}

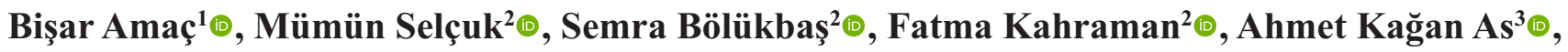 \\ Muhammed Savran ${ }^{4} \oplus$, Orhan Güvenç ${ }^{5}$, Mehmet Tuğrul Göncü̈ ${ }^{\circledR}$, Mesut Engin $^{3} \odot$, Şenol Yavuz $^{3} \odot$
}

\author{
${ }^{1}$ Department of Cardiovascular Surgery, Division of Perfusion, University of Health Sciences, Mehmet Akif Inan Training and Research \\ Hospital, Şanliurfa, Turkey \\ ${ }^{2}$ Department of Cardiovascular Surgery, Division of Perfusion, University of Health Sciences, Bursa Yüksek Ihtisas Training and \\ Research Hospital, Bursa, Turkey \\ ${ }^{3}$ Department of Cardiovascular Surgery, University of Health Sciences, Bursa Medical Faculty, Bursa Yüksek İhtasas Training and \\ Research Hospital, Bursa, Turkey \\ ${ }^{4}$ Department of Cardiovascular Surgery, A $\breve{g r l}$ State Hospital, A Ărr, Turkey \\ ${ }^{5}$ Department of Cardiovascular Surgery, Bursa Uludağ University, Medical Faculty, Bursa, Turkey
}

\begin{abstract}
In most adult cardiac surgery operations, the heart must be completely immobile and isolated from the blood. Therefore, the heart is stopped in diastole and a still operative site is obtained. Cardiac arrest results in ischemiareperfusion injury. For these reasons, myocardial protection and the prevention of damages are required. Various cardioplegia solutions are used for this purpose. It can be said that cardioplegia is the gold standard method of myocardial protection in cardiac arrest. Nowadays, "Single-dose cardioplegia" applications are increasingly used, especially in minimally invasive cardiac surgery and basic coronary bypass procedures due to the advantages they provide, which include reduction of aortic cross-clamp time, prevention of frequent interruption of the procedure due to cardioplegia, and reduced postoperative myocardial dysfunction incidence. The two main solutions used in single dose cardioplegia applications are the Bretschneider solution and the del Nido extracellular cardioplegia solution. The del Nido cardioplegia solution (dNCS), which was originally developed for use in pediatric cardiac surgery, has recently increased its use in adult cardiac surgery due to straightforward application and long-term effectiveness. The del Nido cardioplegia reduces the aortic cross clamp duration, cardiopulmonary bypass time and required cardioplegia solution volume, and is a safer and superior cardioplegia solution and technique in terms of myocardial protection with regards to many organs and cardiacbiochemical parameters.
\end{abstract}

Keywords: Del Nido cardioplegia, adult cardiac surgery, myocardial protection, cardioplegia, cardiopulmonary bypass

$I^{n}$ $\mathrm{n}$ most cardiac surgery operations, the heart must be completely immobile and isolated from the blood. Cardiac arrest and reperfusion also bring about myocardial damage. For these reasons, various protective and preventive measures have emerged for myocardial protection [1], including cardioplegia and non-cardioplegic methods, some of which include hypothermia, fibrillatory arrest and ischemic preparation / preconditioning. Cardioplegia, otherwise known as the pharmacological method, is achieved with cardioplegic solutions. It is an essential and indispensable method of myocardial protection in all cardiac surgery 
procedures in which the heart must be stopped [2].

Crystalloid and blood cardioplegia are used for conventional cardioplegia. Its effectiveness was tried to be increased by various additives to the solutions $[3,4]$. A good and effective cardioplegia solution must be able to provide a rapid diastolic arrest to reduce the use of high energy phosphate compounds (Adenosine Triphosphate [ATP] and phosphocreatine) in myocardial cells. In addition, it should prevent permanent damage by reducing reperfusion damage in myocardial protection [5]. There are many cardioplegia solutions and application methods. The purpose is to allow the safe application of cardiac surgery, ensure that the patient safely exits from cardiopulmonary bypass and to prevent any damage and toxic effect to the heart and all other organs in the postoperative period [6]. Diversity and research in this field have increased because of the differing contents used in the preparation of cardioplegia solutions for myocardial protection for many years $[7,8]$. One of the current and effective cardioplegic solutions used in recent years is the del Nido cardioplegia solution (dNCS).

In this study, we aimed to discuss the use of dNCS in adult cardiac surgery in light of the current literature.

\section{History}

The scientists who pioneered the development of cardioplegia are Bretschneider, Spieckman, Kirsch, and Hoelscher. The concept of stopping the electromechanical activity of the heart came to the fore in the 1950 s to reduce ischemia reperfusion injury. At that time, the cardioplegic agent used was Melrose solution [9].

The dNCS was first used in Boston Children's Hospital. This solution, which was originally developed for use in pediatric and pediatric cardiac surgery $[10,11]$ has now become widespread in adult cardiac surgery. In the early 1990s, researchers at the University of Pittsburgh, Pedro del Nido, Hung Cao-Danh, K. Eric Sommers, and Akihiko Ohkado, developed a new cardioplegia solution for myocardial protection called the dNCS in the literature and clinical practice [12]. The dNCS has been used successfully in adult cardiac surgery since 2003 [13].

\section{Structure and Metabolism of the Myocardium}

The main contractile unit of the myocardium are myocytes. The basal membrane, located on the inner and outer layers, connects myocytes to each other and the external environment. The sarcolemma with myofibril content surrounding the myocytes is located under the basement membrane. Myofibrils consist of actin and myosin. These myofilaments ensure the contraction and pumping function of the heart. There are many mitochondria in myocardial cells. Having a large number of mitochondria is of great importance for aerobic respiration [14].

The energy required for the contraction of the heart muscle is obtained from ATP. In cases of ischemia and hypoxia, the necessary energy is provided by glycogen. When aerobic metabolism cannot provide enough energy, anaerobic glycolysis takes over. Adenosine monophosphate and lactate accumulates in anaerobic metabolism. Energy synthesis is inhibited by the accumulation of lactate. Under normal conditions with energy deficit, the phosphofructokinase enzyme is active, however, in ischemic conditions it is not activated, and glucose production does not occur. Consequently, cell destruction and hypoxia are observed $[15,16]$.

\section{Myocardial Protection}

Preservation of the myocardium is the most fundamental point of cardiac surgery. Myocardial protection is important both during and after the operation in terms of preserving hemodynamic conditions and preventing morbidity and mortality. Myocardial protection is provided by mechanical and pharmacological methods. Since the myocardium is subject to prolonged ischemia in cardiac surgery, special attention should be paid to the protection of myocardium and endothelium. Cardioplegic solutions are used to prevent myocardial dysfunction due to ischemia during and after cardiac surgery. Choosing the appropriate cardioplegia solution is particularly important to prevent ischemia-reperfusion injury and related adverse events [17].

\section{Cardioplegia}

Cardioplegia is a current and important myocardial protection method. It is the gold standard of myocardial protection in cardiac arrest. Cardioplegic solutions are hyperkalemic, which creates a depolarized positive resting state that brings about arrest. Cardioplegic arrest reduces myocardial oxygen and energy consump- 
tion. Cardioplegia solution stops the heart rapidly in diastole and consequently reduces the energy consumption of myocardial cells and ischemia-reperfusion damage [18].

The mechanisms required for a cardioplegic solution to provide effective protection are as follows [19]:

1. Arrest: To reduce energy consumption and relieve myocardium, diastolic arrest should be fast and effective.

2. Protection: To protect the myocardium, ischemia-reperfusion damage must be minimized, and irreversible damage, prevented.

3. Reversibility: The functions of the heart should be able to restart quickly, easily, and effectively.

4. Minimum toxicity: It should have minimal toxic effect on the heart and all other organs postoperatively.

\section{Del Nido Cardioplegia Solution (dNCS)}

Many cardiac surgeries can be performed easily under cardiac arrest with cardioplegia. Although the dNCS has been used in pediatric surgery centers for many years, it has recently been used in adult cardiac surgery as well. The straightforward application of del Nido cardioplegia solution and its long-term effectiveness have increased its use in adult cardiac surgery [20]. In addition, it has been shown to provide 9,300 dollars of cost advantage in 100 cases [21].

Adult dNCS is an extracellular solution mixed with autologous blood obtained from the extracorporeal circuit. The crystalloid to blood ratio is $4: 1$. The dNCS protocol for adult patients is $20 \mathrm{ml} / \mathrm{kg}$ with a maximum dose of $1000 \mathrm{~mL}$ for patients weighing 50 $\mathrm{kg}$ or more. It provides effective myocardial protection for around 90 minutes. If the aortic cross clamp time is expected to be less than 30 minutes, a half dose of the dNCS is used to arrest the heart. After 90 minutes of aortic cross clamping, it should be decided how much dNCS will be given again depending on the duration of the surgical procedure to be performed. The application pressure of cardioplegia should be at the level of 100-200 $\mathrm{mmHg}$. The dNCS is given as cold cardioplegia at $4^{\circ} \mathrm{C}$. It can be administered antegradely or retrogradely. Additional doses of the dNCS may be given in patients with aortic insufficiency, hypertrophic hearts, coronary disease and in cases where the effectiveness of the given dose is insufficient [20].

In the preparation of the crystalloid component of the dNCS, Plasma-Lyte A, mannitol, magnesium sulfate, bicarbonate, potassium, and lidocaine are used (Table 1). The $\mathrm{pH}$ of the solution is 7.4. A modified $1000 \mathrm{~mL}$ dNCS comprises $200 \mathrm{ml}$ blood (4:1) in a balanced solution containing $26 \mathrm{mEq} / \mathrm{L}$ potassium chlo-

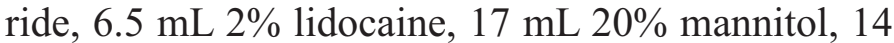
$\mathrm{mL} 15 \%$ magnesium sulfate, and $13 \mathrm{mEq} / \mathrm{L}$ sodium bicarbonate (Table 2) [13].

Plasma Lyte A: It is a basic solution with a $\mathrm{pH}$ value of 7.4 containing $140 \mathrm{mmol} / \mathrm{L}$ sodium, $5 \mathrm{mEq} / \mathrm{L}$ potassium, $3 \mathrm{mEq} / \mathrm{L}$ magnesium, $98 \mathrm{mEq} / \mathrm{L}$ chloride, $27 \mathrm{mEq} / \mathrm{L}$ acetate, and $23 \mathrm{mEq} / \mathrm{L}$ gluconate:

1. Mannitol: Balances osmotic pressure and acts as a free radical scavenger.

2. Magnesium sulfate: It is a natural calcium channel blocker and provides myocardial healing.

3. Sodium bicarbonate: Used as a buffer to re-

\section{Table 1. Original del Nido cardioplegia solution content}

\begin{tabular}{lc}
\hline Content & Volume \\
\hline Plasma-Lyte A & $1000 \mathrm{~mL}$ \\
\hline Mannitol 20\% $^{2}$ & $16.3 \mathrm{~mL}$ \\
$\mathrm{MgSO}_{4} 50 \%$ & $4 \mathrm{~mL}$ \\
$\mathrm{NaHCO}_{3} 8.4 \%$ & $13 \mathrm{~mL}$ \\
$\mathrm{KCL} 2 \mathrm{mEq} / \mathrm{mL}$ & $13 \mathrm{ml}$ \\
\hline Lidocaine $1 \%$ & $13 \mathrm{~mL}$ \\
\hline Patient blood & $\begin{array}{c}200 \mathrm{ml}(20 \% \text { of del Nido } \\
\text { cardioplegia solution) }\end{array}$ \\
\hline
\end{tabular}

Table 2. Modified del Nido cardioplegia solution content

\begin{tabular}{lc}
\hline Content & Volume \\
\hline $\begin{array}{l}\text { Balanced electrolyte } \\
\text { solution }\end{array}$ & $1000 \mathrm{~mL}$ \\
Mannitol $20 \%$ & $17 \mathrm{~mL}$ \\
$\mathrm{MgSO}_{4} 15 \%$ & $14 \mathrm{~mL}$ \\
$\mathrm{NaHCO}_{3} 8.4 \%$ & $13 \mathrm{~mL}$ \\
\hline $\mathrm{KCL} 1 \mathrm{mEq} / \mathrm{mL}$ & $26 \mathrm{~mL}$ \\
Lidocaine $2 \%$ & $6.5 \mathrm{~mL}$ \\
Patient blood & $200 \mathrm{ml}(20 \%$ of del Nido \\
& cardioplegia solution) \\
\hline
\end{tabular}


move excess hydrogen ions and maintain intracellular $\mathrm{pH}$.

4. Potassium chloride: Induces myocardial depolarization

5. Lidocaine: Used as a sodium channel blocker and hyperpolarizing agent. Provides sufficient concentration to continuously affect myocardium

6. Patient blood: $20 \%$ of Del Nido cardioplegia is the patient's fully oxygenated blood. Protects aerobic metabolism and provides buffering to ensure anaerobic glycolysis.

Kantathut et al. [22] investigated the use of lactate Ringer's instead of plasma Lyte A, which is the basic solution for the dNCS. They stated that plasma Lyte A is not found in many countries, which prevents the use of the dNCS. In their study, they used lactat Ringer's solution instead of plasma Lyte A and aimed to evaluate its effect on myocardial protection and clinical results. They reported comparable results with dNCS with plasma Lyte A and stated that cardiac surgery centers which could not obtain plasma-Lyte could use lactate Ringer's as an alternative [22]. Many cardiac surgery centers now use a balanced solution instead of plasma Lyte A in modified dNCS.

Advantages and Disadvantages of del Nido Cardioplegia Solution

Advantages

Many studies involving cardiac surgeries performed with dNCS report that it is a safer and superior cardioplegia solution and technique in terms of aortic cross clamp duration, cardiopulmonary bypass time, required cardioplegia solution volume and cardiac and many organ and biochemical parameters [23-25]. In a meta-analysis including 5516 patients from 10 randomized controlled studies, including a larger patient and study series, and 13 cohort studies with propensity-score match analysis, authors revealed that dNCS shortened operation times compared to multidose cardioplegia, while decreasing reperfusion-related fibrillation rates, and postoperative cardiac enzyme levels [26]. Subsequently, in a study, microembolism was scanned by monitoring with transcranial Doppler ultrasonography and middle cerebral artery control at the time of cardioplegia and crossclamping. This study revealed that the single dose dNCS strategy led to less cerebral microembolism compared to conventional multi-dose cardioplegia [27].
In a systematic review and meta-analysis including one randomized controlled trial, 7 revised observational studies, and 5 uncorrected observational studies conducted between 1996 and 2017; the authors found no difference between the groups in terms of in-hospital mortality [28]. Aortic crossclamp time, CPB times, cardioplegia volume and postoperative troponin levels were lower in the dNCS group. Based on these results, the authors concluded that dNCS could be a safe alternative to blood cardioplegia and potentially provide better myocardial protection [28].

\section{Disadvantages}

There are also some concerns related to the dNCS. One of the major problem is that the dNCS solution has about 300 variations of the formula with the same name but with different chemical combinations. In coronary artery disease, a uniform distribution is not guaranteed owing to the presence of diffuse vessel disease and impaired microcirculation. Residual potassium due to the high potassium content of dNCS may cause coronary vasoconstriction and consequently complicate myocardial ischemia [29]. Also the dNCS has a low nutrient content of $21 \mathrm{kcal} / \mathrm{L}$. An energy-depleted myocardium will be affected by low energy levels [30]. And, infusing multiple doses of dNCS may lead to increased myocardial concentration of lidocaine, resulting in lidocaine toxicity, which is associated with peripheral vasodilation, negative inotropy, ventricular arrhythmias, and seizure [31].

\section{Storage of del Nido Cardioplegia Solution}

In clinics where dNCS is used, it is prepared in the hospital just before surgery. After obtaining information about the efficiency and reliability of the studies, studies were carried out on the storage conditions. Lackner et al. [32] investigated the storage of lidocaine in glass and polyvinyl chloride (PVC) containers in solutions containing potassium chloride, sodium bicarbonate, dextrose, and sodium chloride. Lidocaine concentrations were significantly reduced in PVC bags stored at $22^{\circ} \mathrm{C}$ and underfilled PVC bags stored at $4^{\circ} \mathrm{C}$. The authors concluded that the lidocaine structure remained stable when the solutions were stored in glass containers or large-volume PVC containers in the refrigerator [32]. Pereira et al. [33] reported that the lidocaine concentrations in dNCS solutions stored in ethylene-vinyl acetate (EVA) bags for 30 days at 
$4^{\circ} \mathrm{C}$ remained $95.8 \%$ but decreased to $67 \%$ within 30 days at $35^{\circ} \mathrm{C}$ and $50 \%$ was lost within 30 days at $70^{\circ} \mathrm{C}$. The authors stated that dNCS was stable for at least 30 days under $4^{\circ} \mathrm{C}$ cooling in EVA bags [33].

Křižžek et al. [34] conducted an up-to-date study, in which possible chemical changes in the content of cardioplegia solution according to the content of the storage material and the elapsed time were investigated. Six different dNCS were prepared based on the content of magnesium ions and sodium bicarbonate, which were kept in EVA bags or glass storage containers. All these variants were evaluated for stability while stored at $4^{\circ} \mathrm{C}, 22^{\circ} \mathrm{C}$ and $50^{\circ} \mathrm{C}$. The concentrations of the components were monitored using high pressure liquid chromatography and capillary electrophoresis, and it was found that dNCS remained stable for 8 weeks at $4^{\circ} \mathrm{C}$, and replacement of magnesium chloride with magnesium sulfate and/or presence of sodium bicarbonate had no effect on stability. It has also been shown that if the dNCS was not cooled or kept at a high temperature, the concentration of lidocaine in the solution stored in EVA bags may change significantly with the adsorption of lidocaine to the infusion bag material (within 25 days, the lidocaine concentration dropped to half of its original value). Therefore, the authors concluded that dNCS stored in EVA bags should be kept at $4^{\circ} \mathrm{C}$ to prevent changes in its pharmacological effect [34].

\section{CONCLUSION}

In adult cardiac surgery operations, the dNCS is more advantageous than other cardioplegia solutions in many ways. Many studies report that dNCS reduces aortic cross-clamp duration, cardiopulmonary bypass time and required cardioplegia solution volume, is a safer and satisfactory cardioplegia solution in terms of myocardial protection, many organs, and cardiac-biochemical parameters. The del Nido cardioplegia can be used as a safe and effective solution in adult cardiac surgery.

\section{Authors' Contribution}

Study Conception: BA; Study Design: BA, MS, SB, FK; Supervision: AKA, MS, OG, MTG, ME; Funding: AKA, ME; Materials: MS, SB, FK; Data Collection and/or Processing: BA, ME; Statistical
Analysis and/or Data Interpretation: BA, MS, SB, FK, OG; Literature Review: BA, ME; Manuscript Preparation: $\mathrm{BA}, \mathrm{MS}, \mathrm{SB}, \mathrm{FK}, \mathrm{AKA}, \mathrm{MS}, \mathrm{OG}, \mathrm{MTG}, \mathrm{ME}$, ŞY and Critical Review: BA, MS, SB, FK, AKA, MS, OG, MTG, ME, ŞY.

\section{Conflict of interest}

The authors disclosed no conflict of interest during the preparation or publication of this manuscript.

\section{Financing}

The authors disclosed that they did not receive any grant during conduction or writing of this study.

\section{REFERENCES}

1. Chambers DJ. Mechanisms and alternative methods of achieving cardiac arrest. Ann Thorac Surg 2003;75:S661-6.

2. Yamamoto H, Yamamoto F. Myocardial protection in cardiac surgery: a historical review from the beginning to the current topics. Gen Thorac Cardiovasc Surg 2013;61:485-96.

3. Ferguson ZG, Yarborough DE, Jarvis BL, Sistino JJ. Evidencebased medicine and myocardial protection-where is the evidence? Perfusion 2017;21:30-5.

4. Braathen B, Jeppsson A, Scherste'n H, Hagen OM, Vengen Ø, Rexius $\mathrm{H}$, et al. One single dose of histidine-tryptophan-ketoglutarate solution gives equally good myocardial protection in elective mitral valve surgery as repetitive cold blood cardioplegia: a prospective randomized study. J Thorac Cardiovasc Surg 2011;141:995-1001.

5. Dobson GP, Jones MW. Adenosine and lidocaine: a new concept in nondepolarizing surgical myocardial arrest, protection, and preservation. J Thorac Cardiovasc Surg 2004;127:794-805. 6. Gorgy A, Shore-Lesserson L. Del Nido cardioplegia should be used in all adults undergoing cardiac surgery: Con. J Cardiothorac Vasc Anesth 2019; 33:1791-4.

7. Talwar S, Bhoje A, Sreenivas V, Makhija N, Aarav S, Choudhary SK, et al. Comparison of del Nido and St Thomas cardioplegia solutions in pediatric patients: a prospective randomized clinical trial. Semin Thorac Cardiovasc Surg 2017;29:366-74.

8. Ramani J, Malhotra A, Wadhwa V, Garg P, Tarsaria M, Pandya H. Single-dose lignocaine based blood cardioplegia in single valve replacement patients. Braz J Cardiovasc Surg 2017;32:905 .

9. Melrose DG, Dreyer B, Bentall HH, Baker JB. Elective cardiac arrest. Lancet 1955;269:21-2.

10. del Nido PJ, Cao Danh H, Sommers KE, Ohkado A. An aqueous heart preservation and cardioplegia solution. Chem Abstr 1995;123:29054 (US Patent 5,407,793, Apr 18, 1995).

11. Spratt JR, Guleserian KJ, Shumway SJ. Historical perspectives of the American Association for Thoracic Surgery: Pedro J. del Nido. J Thorac Cardiovasc Surg 2017;153:225-7.

12. Matte GS, del Nido PJ. History and use of del Nido cardio- 
plegia solution at Boston Children's Hospital. J Extra Corpor Technol 2012;44:98-103.

13. Sanetra K, Pawlak I, Cisowski M. Del Nido cardioplegia what is the current evidence? Kardiochir Torakochirurgia Pol 2018;15:114-8.

14. Marieb EN, Hoehn K, Cardiac Muscle Fibers, In: S. Beauparlant (Ed), Human Anatomy \& Physiology, Ninth Edition Pearson, Boston. 2013: p. 671-74.

15. Maxwell SRJ, Lip GYH. Reperfusion injury: a review of the pathophysiology, clinical manifestations and therapeutic options. Int J Cardiol 1997;58:95-117.

16. Park JL, Lucchesi BR. Mechanisms of myocardial reperfusion injury. Ann Thorac Surg 1999;68:1905-12.

17. Vinten-Johansen J. Whole blood cardioplegia: do we still need to dilute? J Extra Corpor Technol 2016;48:P9-P14.

18. Durandy YD. Is there a rationale for short cardioplegia redosing intervals? World J Cardiol 2015;7:658-64.

19. Comentale G, Giordano R, Palma G. Comparison of the different cardioplegic strategies in cardiac valves surgery: who wins the "arm-wrestling"? J Thorac Dis 2018;10:714-7.

20. Orak Y, Kocarslan A, Boran OF, Acıpayam M, Eroglu E, Kirisci M, et al. Comparison of the operative and postoperative effects of del Nido and blood cardioplegia solutions in cardiopulmonary bypass surgery. Braz J Cardiovasc Surg 2020;35:689-96. 21. Timek T, Willekes C, Hulme O, Himelhoch B, Nadeau D, Borgman A, et al. Propensity matched analysis of del Nido cardioplegia in adult coronary artery bypass grafting: initial experience with 100 consecutive patients. Ann Thorac Surg 2016;101:2237-41.

22. Kantathut N, Cherntanomwong P, Khajarern S, Leelayana P. Lactated Ringer's as a base solution for del Nido cardioplegia. J Extra Corpor Technol 2019;51:153-9.

23. Luo W, Bouhout I, Demers P. The del Nido cardioplegia in adult cardiac surgery: reinventing myocardial protection? J Thorac Dis 2019;11(Suppl 3):S367-9.

24. Eris C, Engin M, Erdolu B, Kagan As A. Comparison of del Nido cardioplegia vs blood cardioplegia in adult aortic surgery is the single-dose cardioplegia technique really advantageous?
Asian J Surg. 2021 Oct 11. doi: 10.1016/j.asjsur.2021.09.032. 25. Sanrı US, Özsin KK, Toktaş F, Yavuz Ş. Comparison of Del Nido cardioplegia and blood cardioplegia in terms of development of postoperative atrial fibrillation in patients undergoing isolated coronary artery bypass grafting. Braz J Cardiovasc Surg 2021;36:158-64.

26. Gambardella I, Gaudino MFL, Antoniou GA, Tranbaugh RF, Nappi F, Girardi LN. Single versus multidose cardioplegia in adult cardiac surgery patients: a meta-analysis. J Thorac Cardiovasc Surg 2020;160:1195-1202.e12.

27. Mukdad L, Toppen W, Sanaiha Y, Mantha A, Bland S, Shemin $\mathrm{R}$, et al. Incidence of cerebral microemboli in single-dose vs. multidose cardioplegia in adult cardiac surgery. J Extra Corpor Technol 2018;50:143-8.

28. An KR, Rahman IA, Tam DY, Ad N, Verma S, Fremes SE, et al. A systematic review and meta-analysis of del Nido versus conventional cardioplegia in adult cardiac surgery. Innovations (Phila) 2019;14:385-93.

29. Kim K, Ball C, Grady P, Mick S. Use of del Nido cardioplegia for adult cardiac surgery at the Cleveland Clinic: perfusion implications. J Extra Corpor Technol 2014;46:317-23.

30. Valooran GJ, Nair SK, Chandrasekharan K, Simon R, Dominic C. del Nido cardioplegia in adult cardiac surgery--scopes and concerns. Perfusion 2016;31:6-14.

31. Lazar HL. Commentary: del Nido cardioplegia-the jury is still out and a new trial is needed. J Thorac Cardiovasc Surg 2020 Sep 18. doi: 10.1016/j.jtcvs.2020.09.053.

32. Lackner TE, Baldus D, Butler CD, Amyx C, Kessler G. Lidocaine stability in cardioplegic solution stored in glass bottles and polyvinyl chloride bags. Am J Hosp Pharm 1983;40:97-101. 33. Pereira LM, Matte GS, Lutz P, Arnold A, Patterson A. Production standard and stability of compounded del Nido Cardioplegia Solution. Hosp Pharm 2017;52:766-73.

34. Křížek T, Kozlík P, Hodek O, Štěpánová E, Nesměrák K. Lidocaine adsorption to ethylenevinyl acetate infusion bags decreases its availability in del Nido cardioplegia solution. Monatsh Chem 2020;151:1217-23. 